\title{
A global synthesis of the effects of diversified farming systems on arthropod diversity within fields and across agricultural landscapes
}

Elinor M. Lichtenberg ${ }^{1,2}$ (D) | Christina M. Kennedy ${ }^{3}$ | Claire Kremen ${ }^{4}$ |

Péter Batáry $^{5}$ D | Frank Berendse ${ }^{6}$ | Riccardo Bommarco ${ }^{7}$ | Nilsa A. Bosque-Pérez ${ }^{8}$ | Luísa G. Carvalheiro $^{9,10}$ | William E. Snyder ${ }^{1}$ | Neal M. Williams ${ }^{11}$ | Rachael Winfree ${ }^{12}$ |

Björn K. Klatt ${ }^{5,13,14}$ | Sandra Åström ${ }^{15}$ | Faye Benjamin ${ }^{12}$ | Claire Brittain ${ }^{11}$ | Rebecca Chaplin-Kramer ${ }^{16}$ | Yann Clough ${ }^{13}$ | Bryan Danforth ${ }^{17}$ | Tim Diekötter ${ }^{18}$ | Sanford D. Eigenbrode $^{8}$ | Johan Ekroos ${ }^{13}$ | Elizabeth Elle ${ }^{19}$ | Breno M. Freitas ${ }^{20}$ | Yuki Fukuda $^{21}$ | Hannah R. Gaines-Day ${ }^{22}$ | Heather Grab ${ }^{17}$ | Claudio Gratton ${ }^{22}$ | Andrea Holzschuh $^{23}$ | Rufus Isaacs ${ }^{24}$ | Marco Isaia ${ }^{25}$ | Shalene Jha ${ }^{26}$ | Dennis Jonason $^{27}$ | Vincent P. Jones ${ }^{28}$ | Alexandra-Maria Klein ${ }^{29}$ | Jochen Krauss ${ }^{23}$ | Deborah K. Letourneau $^{30}$ | Sarina Macfadyen ${ }^{31}$ | Rachel E. Mallinger ${ }^{22}$ | Emily A. Martin ${ }^{23}$ | Eliana Martinez ${ }^{32}$ | Jane Memmott ${ }^{33}$ | Lora Morandin ${ }^{34}$ | Lisa Neame ${ }^{35}$ | Mark Otieno ${ }^{36}$ | Mia G. Park ${ }^{17,37}$ | Lukas Pfiffner ${ }^{38}$ | Michael J. O. Pocock ${ }^{39}$ | Carlos Ponce Co $^{40}$ Simon G. Potts ${ }^{41}$ | Katja Poveda ${ }^{17}$ | Mariangie Ramos $^{42}$ | Jay A. Rosenheim ${ }^{11}$ | Maj Rundlöf ${ }^{14}$ | Hillary Sardiñas ${ }^{4}$ | Manu E. Saunders ${ }^{43}$ (D) Nicole L. Schon ${ }^{44}$ | Amber R. Sciligo ${ }^{4}$ | C. Sheena Sidhu ${ }^{45}$ | Ingolf Steffan-Dewenter ${ }^{23}$ | Teja Tscharntke ${ }^{5}$ | Milan Veselý ${ }^{46}$ | Wolfgang W. Weisser $^{47}$ | Julianna K. Wilson ${ }^{24}$ | David W. Crowder ${ }^{1}$

${ }^{1}$ Department of Entomology, Washington State University, Pullman, WA, USA

${ }^{2}$ Department of Ecology \& Evolutionary Biology, The University of Arizona, Tucson, AZ, USA

${ }^{3}$ Global Lands Program, The Nature Conservancy, Fort Collins, CO, USA

${ }^{4}$ Department of Environmental Sciences, Policy and Management, University of California, Berkeley, CA, USA

${ }^{5}$ Agroecology, University of Goettingen, Göttingen, Germany

${ }^{6}$ Nature Conservation and Plant Ecology Group, Wageningen University, Wageningen, the Netherlands

${ }^{7}$ Department of Ecology, Swedish University of Agricultural Sciences, Uppsala, Sweden

${ }^{8}$ Department of Entomology, Plant Pathology and Nematology, University of Idaho, Moscow, ID, USA

${ }^{9}$ Departamento de Ecologia, Universidade de Brasília, Brasília, Brazil

${ }^{10}$ Center for Ecology, Evolution and Environmental Changes (CE3C), Faculdade de Ciencias, Universidade de Lisboa, Lisboa, Portugal

${ }^{11}$ Department of Entomology and Nematology, University of California, Davis, CA, USA

${ }^{12}$ Department of Ecology, Evolution and Natural Resources, Rutgers University, New Brunswick, NJ, USA

${ }^{13}$ Centre for Environmental and Climate Research, Lund University, Lund, Sweden

${ }^{14}$ Department of Biology, Lund University, Lund, Sweden

${ }^{15}$ Norwegian Institute for Nature Research (NINA), Trondheim, Norway

${ }^{16}$ Natural Capital Project, Stanford University, Stanford, CA, USA

${ }^{17}$ Department of Entomology, Cornell University, Ithaca, NY, USA

${ }^{18}$ Department of Landscape Ecology, Kiel University, Kiel, Germany

${ }^{19}$ Department of Biological Sciences, Simon Fraser University, Burnaby, BC, Canada

${ }^{20}$ Departamento de Zootecnia, Universidade Federal do Ceará, Fortaleza, CE, Brazil 
${ }^{21}$ Centres for the Study of Agriculture Food and Environment, University of Otago, Dunedin, New Zealand

${ }^{22}$ Department of Entomology, University of Wisconsin-Madison, Madison, WI, USA

${ }^{23}$ Department of Animal Ecology and Tropical Biology, Biocenter, University of Würzburg, Würzburg, Germany

${ }^{24}$ Department of Entomology, Michigan State University, East Lansing, MI, USA

${ }^{25}$ Department of Life Sciences and Systems Biology, University of Torino, Torino, Italy

${ }^{26}$ Department of Integrative Biology, University of Texas at Austin, Austin, TX, USA

${ }^{27}$ Department of Physical Geography, Stockholm University, Stockholm, Sweden

${ }^{28}$ Department of Entomology, Tree Fruit Research and Extension Center, Washington State University, Wenatchee, WA, USA

${ }^{29}$ Nature Conservation and Landscape Ecology, Faculty of Environment and Natural Resources, University of Freiburg, Freiburg, Germany

${ }^{30}$ Department of Environmental Studies, University of California, Santa Cruz, CA, USA

${ }^{31} \mathrm{CSIRO}$, Acton, ACT, Australia

${ }^{32}$ CORPOICA, Centro de Investigación Obonuco, Pasto, Colombia

${ }^{33}$ School of Biological Sciences, University of Bristol, Bristol, UK

${ }^{34}$ Pollinator Partnership Canada, Victoria, BC, Canada

${ }^{35}$ Alberta Environment and Parks, Regional Planning Branch, Edmonton, AB, Canada

${ }^{36}$ Department of Agricultural Resource Management, Embu University College, Embu, Kenya

${ }^{37}$ Department of Humanities \& Integrated Studies, University of North Dakota, Grand Forks, ND, USA

${ }^{38}$ Department of Crop Science, Research Institute of Organic Agriculture, Frick, Switzerland

${ }^{39}$ NERC Centre for Ecology \& Hydrology, Wallingford, UK

${ }^{40}$ Department of Evolutionary Ecology, Museo Nacional de Ciencias Naturales, CSIC, Madrid, Spain

${ }^{41}$ Centre for Agri-Environmental Research, School of Agriculture, Policy and Development, University of Reading, Reading, UK

${ }^{42}$ Department of Agricultural Technology, University of Puerto Rico at Utuado, Utuado, PR, USA

${ }^{43}$ Institute for Land Water \& Society, Charles Sturt University, Albury, NSW, Australia

${ }^{44} \mathrm{AgResearch}$, Lincoln Research Centre, Christchurch, New Zealand

${ }^{45}$ University of California Cooperative Extension, San Mateo \& San Francisco Counties, Half Moon Bay, CA, USA

${ }^{46}$ Department of Zoology, Faculty of Science, Palacký University, Olomouc, Czech Republic

${ }^{47}$ Terrestrial Ecology Research Group, Department for Ecology and Ecosystem Management, School of Life Sciences Weihenstephan, Technical University of Munich, Freising, Germany

\section{Correspondence}

Elinor M. Lichtenberg, Department of Integrative Biology, University of Texas at Austin, Austin, TX, USA.

Email: elichten@utexas.edu

\section{Present address}

Elinor M. Lichtenberg, Department of Integrative Biology, University of Texas at Austin, Austin, TX, USA

\section{Funding information}

National Institute of Food and Agriculture, U.S. Department of Agriculture, Grant/ Award Number: 2014-51106-22096; National Council for Scientific and Technological Development-CNPq, Grant/ Award Number: 305062/2007-7; Felix Trust; STEP Project, Grant/Award Number: EC FP7 244090

\section{Abstract}

Agricultural intensification is a leading cause of global biodiversity loss, which can reduce the provisioning of ecosystem services in managed ecosystems. Organic farming and plant diversification are farm management schemes that may mitigate potential ecological harm by increasing species richness and boosting related ecosystem services to agroecosystems. What remains unclear is the extent to which farm management schemes affect biodiversity components other than species richness, and whether impacts differ across spatial scales and landscape contexts. Using a global metadataset, we quantified the effects of organic farming and plant diversification on abundance, local diversity (communities within fields), and regional diversity (communities across fields) of arthropod pollinators, predators, herbivores, and detritivores. Both organic farming and higher in-field plant diversity enhanced arthropod abundance, particularly for rare taxa. This resulted in increased richness but decreased evenness. While these responses were stronger at local relative to regional scales, richness and abundance increased at both scales, and richness on farms embedded in complex relative to simple landscapes. Overall, both organic farming and in-field plant diversification exerted the strongest effects on pollinators and predators, suggesting these management schemes can facilitate ecosystem service providers without augmenting herbivore (pest) populations. Our results suggest that organic farming and plant diversification promote diverse arthropod metacommunities that may provide temporal and spatial stability of ecosystem service provisioning. Conserving diverse plant and arthropod communities in farming systems therefore requires sustainable practices that operate both within fields and across landscapes. 
KEYWORDS

agricultural management schemes, arthropod diversity, biodiversity, evenness, functional groups, landscape complexity, meta-analysis, organic farming, plant diversity

\section{1 | INTRODUCTION}

Simplification of agricultural landscapes, and increased use of fertilizers and pesticides, threaten arthropod communities worldwide (Matson, Parton, Power, \& Swift, 1997; Potts et al., 2016; Tscharntke, Klein, Kruess, Steffan-Dewenter, \& Thies, 2005). This could impair agricultural sustainability because declines in arthropod abundance and diversity are often associated with reduced provisioning of ecosystem services including pollination, pest control, and nutrient cycling (Kremen \& Miles, 2012; Oliver et al., 2015). Two strategies purported to mitigate this ecological harm are organic farming and in-field plant diversification (Table S1). We refer to these strategies as farm management schemes, both of which include a host of practices that promote biological diversification (Kremen \& Miles, 2012; Puech, Baudry, Joannon, Poggi, \& Aviron, 2014). We refer to organic farming, conventional farming, high in-field plant diversification, and low in-field plant diversification as separate field types. Mounting evidence indicates that arthropod communities are more diverse and abundant in fields lacking synthetic fertilizers and pesticides, and in those with greater plant diversity (e.g., intercropped or having noncrop vegetation like hedgerows or floral strips) (Batáry, Dicks, Kleijn, \& Sutherland, 2015; Crowder, Northfield, Gomulkiewicz, \& Snyder, 2012; Fahrig et al., 2015; Garibaldi et al., 2014; Kennedy et al., 2013; Letourneau et al., 2011).

The benefits of diversified farming practices may manifest at different scales, such as within individual fields (local diversity) or across multiple fields in a landscape (regional diversity) (Table S1). One observational study of 205 farms across Europe and Africa, for example, found that although organic farming provided strong benefits for local richness of plants and pollinators, these benefits faded at regional scales (Schneider et al., 2014). This suggests that while farmers may promote local diversity on their field(s) by using organic practices, their efforts may not enhance biodiversity across multiple fields. Conversely, the addition of hedgerows to crop fields has been shown to increase community heterogeneity and species turnover (measures of local diversity), which are important components of regional diversity (Ponisio, M'Gonigle, \& Kremen, 2016). The effects of farm management for particularly mobile arthropods, such as pollinators, may also transcend individual fields if the improved quality of habitats on one field boosts abundance, with organisms spilling over to nearby fields (Kennedy et al., 2013; Tscharntke et al., 2012). While increases in local diversity have been shown to provide the strongest benefits to individual ecosystem services (i.e., pollination and biological control), regional diversity can support the simultaneous provision of multiple ecosystem services over space and time (Pasari, Levi, Zavaleta, \& Tilman, 2013). Thus, to mitigate the effects of biodiversity loss across agroecosystems, farm management schemes should ideally benefit both local and regional diversity.

Research on the impacts of organic farming and in-field plant diversity has primarily focused on beneficial functional groups such as natural enemies and pollinators (Crowder, Northfield, Strand, \& Snyder, 2010; Kennedy et al., 2013) across intensively sampled regions of Europe and North America (De Palma et al., 2016; Shackelford et al., 2013). Moreover, almost all studies rely on richness (the number of taxa; Table S1) as a proxy for biodiversity but ignore metrics such as evenness (the relative abundances among species; Table S1) (e.g., Bengtsson, Ahnström, \& Weibull, 2005; Tuck et al., 2014). Yet, richness poorly reflects overall community diversity (Duncan, Thompson, \& Pettorelli, 2015; Loiseau \& Gaertner, 2015), and its measurement is strongly confounded by abundance (Chao \& Jost, 2012). Variation in richness has also been shown to have minimal impacts on ecosystem functioning when richness increases are driven primarily by rare species that contribute little to ecosystem services (Kleijn et al., 2015; Winfree, Fox, Williams, Reilly, \& Cariveau, 2015). While common species may provide the majority of ecosystem services on some farms (Kleijn et al., 2015; Schwartz et al., 2000), rare species can provide redundancy (Kleijn et al., 2015) or support provisioning of multiple ecosystem services (Soliveres et al., 2016). Assessing evenness can help determine whether richness increases are driven by rare or common species. Richness, evenness, and abundance can also independently or interactively affect ecosystem function (Crowder et al., 2010; Northfield, Snyder, Ives, \& Snyder, 2010; Wilsey \& Stirling, 2006; Winfree et al., 2015; Wittebolle et al., 2009). Thus, teasing apart the effects of farm management schemes on abundance and each diversity metric are critical. While existing studies find that organic farming and in-field plant diversification tend to boost abundance and richness of certain taxa, whether these effects are consistent for other biodiversity components such as evenness, for functional groups other than pollinators and natural enemies, and for less-well studied regions of the world (e.g., the tropics and Mediterranean) remains unclear.

Here, we present a comprehensive synthesis of studies that explore how organic farming and in-field plant diversification influence arthropod communities across global agroecosystems. We determine whether community responses to these management schemes vary based on different metrics (abundance, local richness and evenness, regional richness, and evenness) and arthropod functional groups (detritivores, herbivores, pollinators, and predators). We investigate if these responses depend on landscape complexity (i.e., the proportion of natural and seminatural habitat surrounding the farm; Fig. S1, Table S1), because landscape heterogeneity has been shown to influence the effectiveness of farm management 
schemes (Batáry, Báldi, Kleijn, \& Tscharntke, 2011; Kennedy et al., 2013; Kleijn, Rundlöf, Scheper, Smith, \& Tscharntke, 2011; Tuck et al., 2014). We also explore whether farm management schemes have similar impacts on relatively rare compared to common taxa. Our results demonstrate whether local and regional diversities and abundance of different functional groups are similarly affected by on-farm management and landscape complexity, and the extent of covariance between biodiversity within and across fields in a landscape. Broadly, our findings further reveal the role of farm management in mitigating biodiversity loss and maintaining healthy arthropod communities in agroecosystems under global change.

\section{2 | MATERIALS AND METHODS}

\section{1 | Literature survey}

We compiled data from studies on arthropod diversity in agroecosystems that compared one or both of the farm management schemes of interest: (i) organic vs. conventional farming and (ii) high vs. low in-field plant diversity. We defined organic agriculture as fields that were organically certified or met local certification guidelines (Table S1). These guidelines involve, at minimum, maintaining production systems free of synthetic pesticides and fertilizers. We defined conventional agriculture as fields or farms that used recommended rates of synthetic, or a mix of synthetic and organic, pesticides and fertilizers. Other types of farming systems, such as integrated, that fit neither category where excluded from the analysis. Fields were defined as having high in-field plant diversity if they had diverse crop vegetation or managed field margins to include non-crop vegetation (e.g., hedgerows, border plantings, and flower strips) (Table S1). We also classified small ( $<4$ ha) fields as diverse because they yield small-scale crop diversity (across several fields) even if the target field is a monoculture (Pasher et al., 2013). Fields were defined as having low in-field plant diversity if they had none of these features. Studies that compared these schemes were identified by (i) searching the reference lists of recent meta-analyses (Batáry et al., 2011; Chaplin-Kramer, O'Rourke, Blitzer, \& Kremen, 2011; Crowder et al., 2012; Garibaldi et al., 2013; Kennedy et al., 2013; Scheper et al., 2013; Shackelford et al., 2013), (ii) searching ISI Web of Knowledge (April and May 2013) using the terms "evenness or richness" and "organic and conventional" or "local diversity," and (iii) directly contacting researchers who study arthropods in agricultural systems.

We identified 235 relevant studies that we examined for inclusion based on five criteria: (i) sampling was performed in the same crop or crop type (e.g., cereals) for organic and conventional fields, or fields with high and low in-field plant diversity; (ii) sampling was conducted at the scale of individual crop fields rather than using plots on experiment stations; (iii) the study included at least two fields of each type; (iv) all organisms collected were identified to a particular taxonomic level (i.e., order, family, genus, species, or morphospecies), such that no taxa were lumped into groups such as "other," and ( $v$ ) at least three unique taxa were collected. We use "taxon" to refer to a single biological type (e.g., species, morphospecies, genus, and family), determined as the finest taxonomic resolution to which each organism was identified in a particular study (see examples in Table S1). A total of 60 studies met our criteria, representing 43 crops, 21 countries, and five regions (Asia, Europe, North and Central America, South America, and Oceania) (Fig. S2, Table S2). For studies that investigated both management scheme comparisons, we included the data in both analyses only when the field types were independently assigned (Table S3); otherwise we selected the scheme that the authors indicated the study was designed to address (Table S2). Across these 60 studies, our meta-analysis included 110 unique data points: 81 comparing organic and conventional fields and 29 comparing fields with high vs. low infield plant diversity (Fig. S2, Tables S2, S4, archived data). Among organic vs. conventional studies, the numbers with high in-field plant diversity, low in-field plant diversity, and both levels of plant diversity were independent of organic vs. conventional management $\left(\chi_{2}^{2}=0.47, p=.79\right)$.

\subsection{Calculation of effect sizes}

Unlike traditional meta-analyses that extract summary statistics from studies, we gathered and manipulated raw data, which enabled us to calculate evenness and classify taxa into functional groups. For each study, we compiled data on the abundance of all taxa in each field. For studies conducted across multiple years or crop types, separate values were compiled for each year and crop. To avoid pseudoreplication, for multiyear studies we selected a single year to analyze based on maximizing the number of (i) sites that met the evenness criterion (at least three taxa), (ii) fields, or (iii) individuals (in decreasing priority order; Garibaldi et al., 2013). Each collected taxon was classified into one of four functional groups: detritivore, herbivore, pollinator, or predator (see Supporting Methods for details). These taxon-level data were used to calculate effect sizes for abundance, local diversity, and regional diversity in paired organic vs. conventional or high vs. low in-field plant diversity systems. For local and regional calculations, we defined diversity as both richness and evenness, and treated each functional group separately (Fig. S1).

Local diversity reflects the average diversity within each field and was calculated using individual crop fields as the sampling unit (Fig. S1, Table S1). In studies with subsamples at a scale smaller than a field (i.e., plots within fields), values across these subsamples were averaged before calculating local diversity. Abundance was the number of arthropods, and richness the number of unique taxa, in a field. Evenness was calculated using the metric $E_{v a r}$, which ranges from 0 (one taxon dominant) to 1 (uniform abundance for all taxa). This metric was chosen for its desirable statistical properties, particularly independence from richness, and its use in similar previous metaanalyses (Crowder et al., 2012). After calculating abundance, richness, and evenness for each field, we averaged values across all fields of a particular type in a study to obtain the values for effect size calculations.

Regional diversity values were calculated based on individuals pooled across all fields in a study (Fig. S1, Table S1). Thus, regional 
richness and evenness are measures of diversity of metacommunities across fields in a landscape, while local diversity measures communities in a single field (Wang \& Loreau, 2014). We note that regional diversity is not a direct indication of spatial scale, as the geographical extent of sampling varied among studies. Some studies were not designed to assess regional diversity specifically, and sampled unequal numbers of fields of each type. To correct for this sampling bias, we used sample-based rarefaction with 1,000 random samples taken from the set of fields in a given study to determine pooled species assemblages (Gotelli \& Colwell, 2011). For example, if a study had 10 conventional and six organic fields, regional diversity values for the conventional management schemes would be based on the average pooled community taken from 1,000 random draws of six field sites. Regional abundance is simply local abundance multiplied by the number of sites, thus we reported only one abundance value per study.

To compare effects of farm management schemes on diversity and abundance, we used the log-response ratio as an effect size metric (Hedges, Gurevitch, \& Curtis, 1999). We used this metric, rather than a weighted effect size, for three reasons. First, weighted effect sizes could not be calculated for regional diversity because these calculations were based on a single value (without replication) from each study, such that there was no estimate of variability. Second, our studies classified arthropods at varying levels of taxonomic resolution. Studies classified at the family level had less variability than studies classified at the species level, so using a weighted metric would give studies conducted at a coarser taxonomic resolution greater weight. Finally, preliminary analysis showed that weighted and unweighted analyses of local diversity and abundance were qualitatively similar (Table S5). In the Results, we back-transformed log-response ratio effect sizes to percentages.

We assessed funnel plot asymmetry to test for publication bias. Because we used an unweighted effect size metric, we plotted effect sizes against sample sizes (i.e., number of fields; Figs S3, S4) (Sterne \& Egger, 2001), and visually assessed asymmetry as formal statistical tests require effect size variances (Jin, Zhou, \& He, 2015) and measures of regional diversity had no variance component. Based on our visual assessment, we did not find areas of missing non-significant results, a directional bias to effects, or a strong relationship between effect and sample sizes. We did not detect any sign of publication bias; funnel plots were sufficiently symmetrical. Finally, we ensured the sampling method (active vs. passive sampling techniques) did not influence results (see Supporting Methods, Table S6). We calculated abundance and diversity values with $\mathrm{R} V$. 3.1.1 (R Core Team, 2014), using packages BIODIVERSITYR (Kindt \& Coe, 2005), doBy (Højsgaard \& Halekoh, 2013), and reshape (Wickham, 2007). Data and R scripts are available at https://doi.org/10. 5281/zenodo.439109.

\section{3 | Study variables}

We gathered data on three categorical variables and assessed whether they mediated arthropod responses to farm management schemes: (i) landscape complexity (simple, complex), (ii) biome (boreal, Mediterranean, temperate, and tropical), and (iii) crop cultivation period (annual, perennial). Landscape complexity (see Fig. S1, Table S1) was determined from land cover data on the percentage of natural and seminatural habitat within $1 \mathrm{~km}$ of sampled fields. Natural and seminatural habitats were defined as areas dominated by forest, grassland, shrubland, wetlands, ruderal vegetation, or nonagricultural plantings (i.e., previously cultivated areas where vegetation is regenerating, hedgerows, field margins, and vegetation along roadways or ditches). For each study, we calculated the mean percentage of natural habitats across fields using locally relevant land cover databases. Landscapes were classified as simple if they averaged $\leq 20 \%$ natural habitat, and complex if they averaged $>20 \%$ natural habitat, following Tscharntke et al. (2005) and common practice (e.g., Batáry et al., 2011; Scheper et al., 2013) (see Supporting Methods for additional details). Biome was based on the geographic location of the study. Crop cultivation periods were derived from several sources (FAO AGPC, 2000; Garibaldi et al., 2013). Table S4 shows the distribution of data points across each of these descriptive variables.

\section{4 | Data analyses}

Table S7 summarizes specific questions we addressed and the approach we used to test each one. We first used one-sample ttests (Crowder \& Reganold, 2015) to determine if the mean effect sizes for abundance, local richness and evenness, and regional richness and evenness differed significantly from 0 . For each management scheme comparison (organic vs. conventional or high vs. low in-field plant diversity), these analyses were conducted for the overall arthropod community and for each functional group separately. We also explored correlations between local and regional richness, and between local and regional evenness, to determine if these metrics responded similarly to each of the management schemes. We used $\alpha=0.10$, to describe effect sizes that appeared ecologically important but did not meet the somewhat arbitrary $\alpha=0.05$. This accords with a recent policy statement by the American Statistical Association (Wasserstein \& Lazar, 2016), which notes that reliance on arbitrary alpha values can lead to erroneous conclusions.

In subsequent analyses, we used metaregression to examine whether effect sizes were influenced by functional group and other study characteristics. We excluded studies lacking landscape complexity data (see archived data) from metaregressions. For each management scheme and response, we ran a linear mixed model (LME4 package; Bates, Mächler, Bolker, \& Walker, 2014) that included eight fixed effect variables: (i) functional group (detritivore, herbivore, predator, and pollinator), (ii) diversity scale (local, regional), (iii) landscape complexity (simple, complex), (iv) biome (boreal, Mediterranean, temperate, and tropical), (v) crop cultivation period (annual, perennial), (vi) functional group $\times$ diversity scale interaction, (vii) functional group $\times$ landscape complexity interaction, and (viii) diversity scale $\times$ landscape complexity interaction. These models included 
study ID as a random effect. We used information-theoretic model selection to determine the set of best-fit models for each response variable (MUMIN package; Barton, 2014), which contained models with AICc values within 2 of the smallest value (Burnham \& Anderson, 1998). We examined significance of the fixed effects in each model in the best-fit set $(\alpha=0.10)$ with likelihood ratio tests, and used post hoc planned contrasts (with $p$-values adjusted to control the overall Type I error rate using Holm's sequential Bonferroni procedure; see Supporting Methods) (PHIA package; Rosario-Martinez, 2013) to test for (i) differences in effect size among functional groups and biomes, (ii) differences in effect size between the local and regional scales within each functional group, and (iii) landscape complexity differences between each pair of functional groups.

We also tested whether abundance and richness effect sizes differed for rare and common taxa. Following Kleijn et al. (2015), within each study we classified taxa as common if their relative abundance was at least $5 \%$ of the total community; other species were categorized as rare. We then calculated local abundance and richness as well as regional abundance and richness separately for rare and common taxa. We used one-sample t-tests to determine if mean effect sizes differed significantly from zero, and paired $t$-tests to determine whether mean effect sizes differed between rare and common taxa.

\section{RESULTS}

\subsection{Effects of management schemes on overall arthropod communities}

Organic farming increased arthropod abundance (45\% change), local richness (19\%), and regional richness (11\%) (Figure 1a, Table S8). These positive effects were stronger for local compared to regional richness (Figure 1a, Tables S9, S10). Arthropod communities on organic farms had significantly but only moderately lower local evenness $(-6 \%)$ and regional evenness $(-8 \%)$ than on conventional farms (Figure 1a, Table S8). Fields with high in-field plant diversity increased local richness (23\%) and regional richness (19\%), with similar magnitude (Figure 1b, Tables S8, S11, S12). In-field plant diversity did not significantly affect abundance (27\%), local evenness
(-6\%), or regional evenness (-13\%) (Figure 1b, Table S8). Overall, there were strong positive correlations between local and regional richness $(r=.87)$, and between local and regional evenness $(r=.57$; Fig. S5).

Organic farming increased abundance and richness of both rare and common arthropods at the local and regional scales (Fig. S6a, c, Table S13). At the local scale, organic farming increased arthropod richness by promoting rare taxa ( $27 \%$ increase) more strongly than common taxa (14\% increase) (Fig. S6c, Table S14). In-field plant diversification also had differential effects on rare and common taxa, increasing richness of both at the local scale, but only of rare taxa at the regional scale (Fig. S6d, Table S13). Fields with higher in-field plant diversity increased abundance of common arthropods, but not of rare arthropods (Fig. S6b, Table S13).

\subsection{Effects of management schemes on arthropod functional groups}

Organic farming substantially increased the abundance (90\%), local richness (55\%), and regional richness (32\%) of pollinator communities but did not impact pollinator evenness (Figure 2a, Table S15). For predator communities, organic farming increased abundance (38\%) and local richness (14\%), lowered local (-9\%), and regional (-14\%) evenness (Figure 2c, Table S16), but did not affect regional richness (Figure 2c, Table S16). Organic farming also did not impact abundance, local or regional richness, or local or regional evenness for herbivore (Figure 2e, Table S17), or detritivore (Figure 2g, Table S18) communities. For all biodiversity components and functional groups, effect sizes in response to organic farming did not differ between the local and regional scales (Figure 2a, c, e, f, Tables S9, S10). The diversity scale $\times$ landscape complexity interaction was never retained in a best-fit model (Tables S9, S11).

High in-field plant diversity promoted the abundance (45\%), local richness $(44 \%)$, and regional richness $(29 \%)$ of pollinator communities, but decreased local pollinator evenness (-11\%) (Figure $2 b$, Table S15). In-field plant diversity did not affect regional pollinator evenness (Figure 2b, Table S15). In addition, in-field plant diversity did not alter abundance, local or regional richness, or local or regional evenness for predator (Figure 2d, Table S16) or herbivore
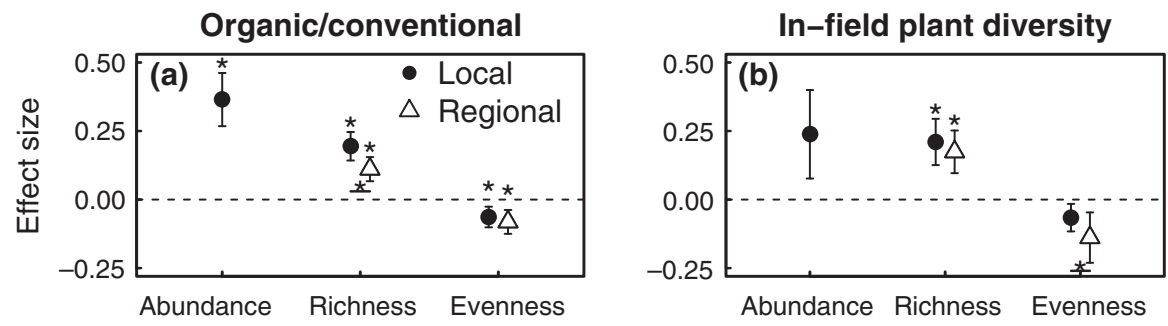

FIGURE 1 Effects of farm management schemes on arthropod abundance, local diversity, and regional diversity. Values shown are for the entire arthropod community, and indicate the mean log-response ratio ( \pm SE) of (a) adopting organic farming and (b) promoting in-field plant diversity on abundance, richness, and evenness. A "*" above a mean effect size denotes a significant difference from zero (determined via onesample $t$-tests; $\alpha=0.1$; statistical details in Tables S8), while one below a pair of means indicates a significant difference between local and regional diversity (determined via linear mixed models; $\alpha=0.1$; Tables S9-S12) 
Organic/conventional
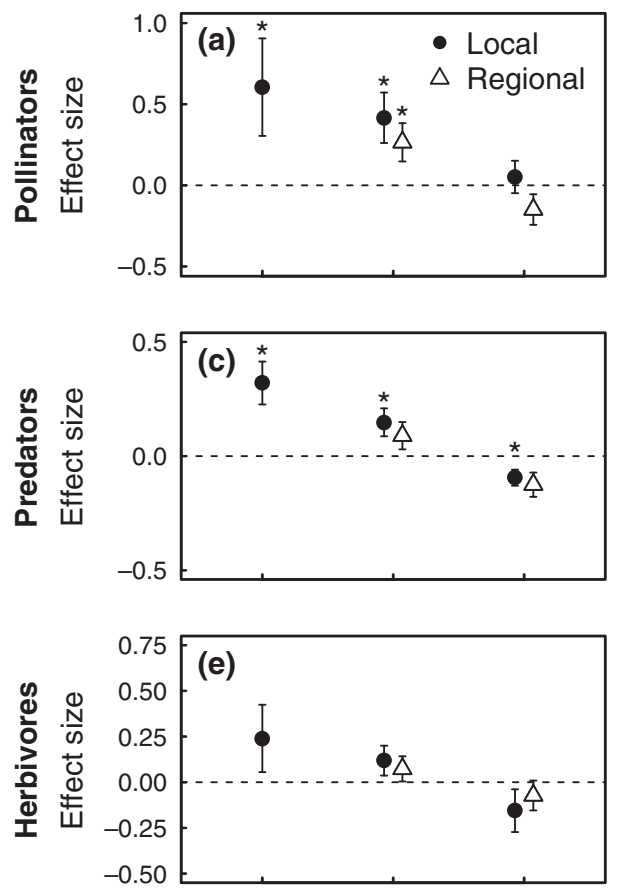

FIGURE 2 Effects of farm management schemes on abundance, local diversity, and regional diversity of arthropod functional groups. Mean log-response ratios $( \pm S E$ ) of (left column) adopting organic farming and (right column) promoting in-field plant diversity for (a, b) pollinators, (c, d) predators, (e, f) herbivores, and $(\mathrm{g}, \mathrm{h})$ detritivores. A "*" above a mean effect size denotes a significant difference from zero (determined via one-sample $t$-tests; $\alpha=0.1$; Tables S15-S18). Metaregressions indicated that differences between local and regional values did not vary with functional group (Tables S9-S12)

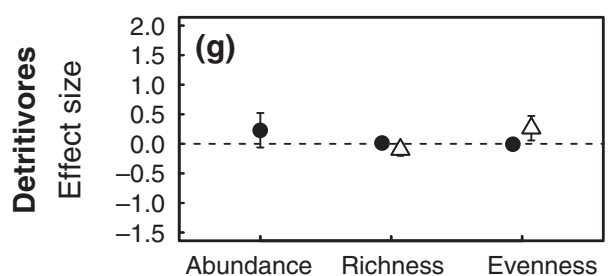

In-field plant diversity
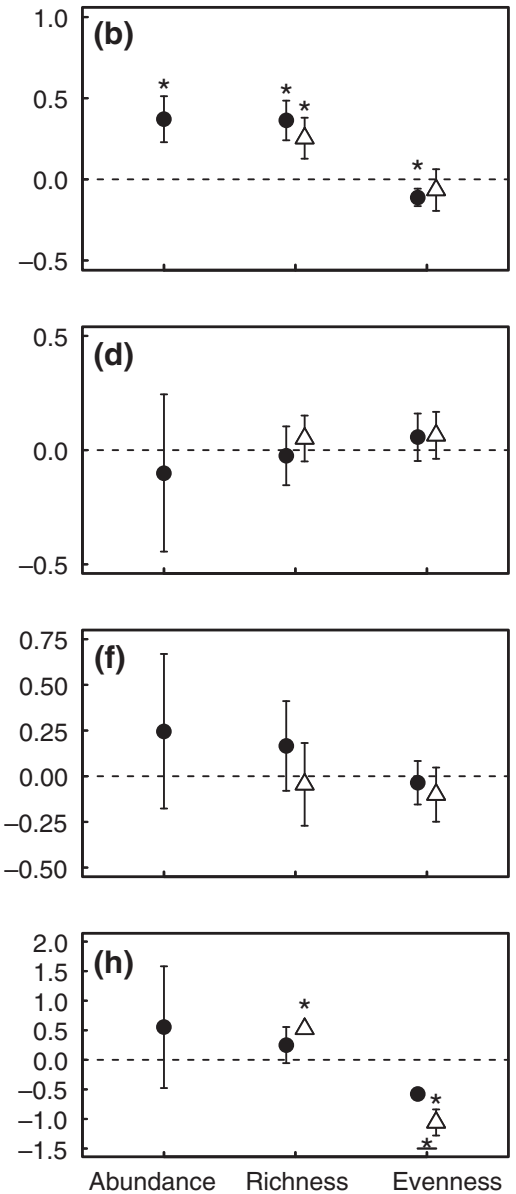

(Figure 2f, Table S17) communities. In-field plant diversity increased the regional richness (69\%) of detritivores and lowered regional detritivore evenness (-65\%), but did not impact detritivore abundance, local richness, or local evenness (Figure $2 \mathrm{~h}$, Table S18). The low sample size for detritivores, however, limits our ability to make inferences about this group.

\subsection{Effects of landscape complexity, biome, and crop cultivation period on arthropod communities}

Landscape complexity did not mediate the influences of organic farming or in-field plant diversity on arthropod abundance or evenness (Figure 3, Tables S9-S12). However, both management schemes had stronger positive effects on local and regional arthropod richness in complex relative to simple landscapes: organic farming $26 \%$ vs. $9 \%$, in-field plant diversification $29 \%$ vs. $11 \%$, respectively (Figure 3c, d, Tables S9-S12). The effects of landscape complexity were similar in both direction and magnitude for local and regional diversity (Figure 3c-e, Tables S9-S12). Organic farming promoted herbivore richness to a greater extent in simple than complex landscapes (Table S10), but other effects of landscape complexity on abundance and diversity were similar across functional groups (Tables S9-S12).
Stronger richness gains in complex than simple landscapes were driven predominantly by rare taxa (Figure 4). In complex landscapes, both organic farming and in-field plant diversification had stronger positive effects on local richness of rare (organic 44\%, plant diversification $68 \%$ ) than of common (organic $21 \%$, plant diversification 18\%) arthropod taxa (Figure 4c, d, Table S19). Organic farming within complex landscapes also increased local abundance and regional richness of rare taxa ( $78 \%$ and $17 \%$, respectively) to a greater extent than common taxa (33\% and $4 \%$, respectively) (Figure $4 a$, Table S19). Neither management scheme differentially affected abundance or richness of rare and common taxa in simple landscapes (Figure 4, Table S19).

Biome mediated the impacts of in-field plant diversity on arthropod richness (pooled across local and regional scales) (Tables S11, S12). Post hoc tests failed to indicate significant differences among biomes when considering all studies; but when the single boreal study was removed from the analysis, high in-field plant diversity more strongly promoted richness in Mediterranean (53\%) than in temperate studies $(-2 \%)$ (Table S12). Biome did not mediate the effects of organic farming or in-field plant diversification on arthropod abundance or evenness (Tables S9-S12). Organic farming increased arthropod abundance to a greater extent in annual (70\%) than in perennial (1\%) crops (Tables S9, S10). The effects of in-field 

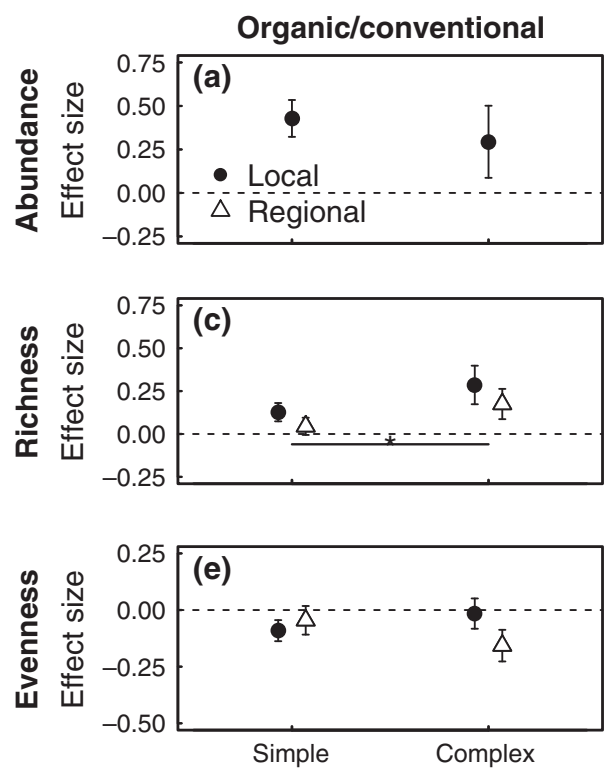

\section{Organic/conventional}
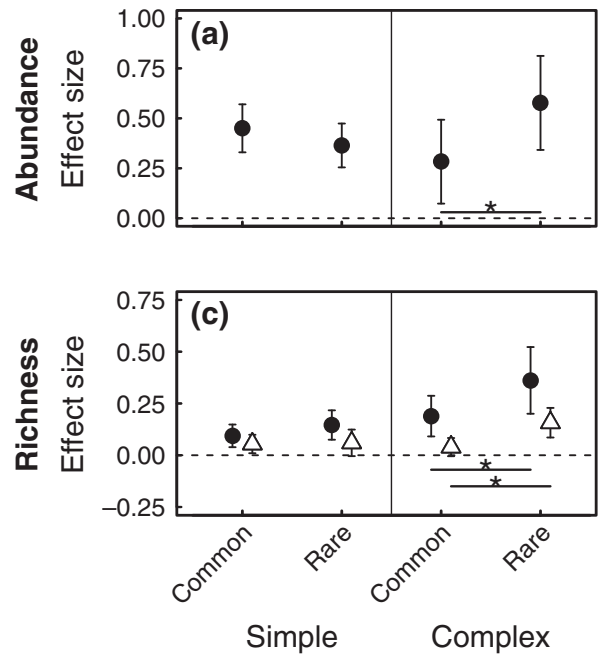

In-field plant diversity
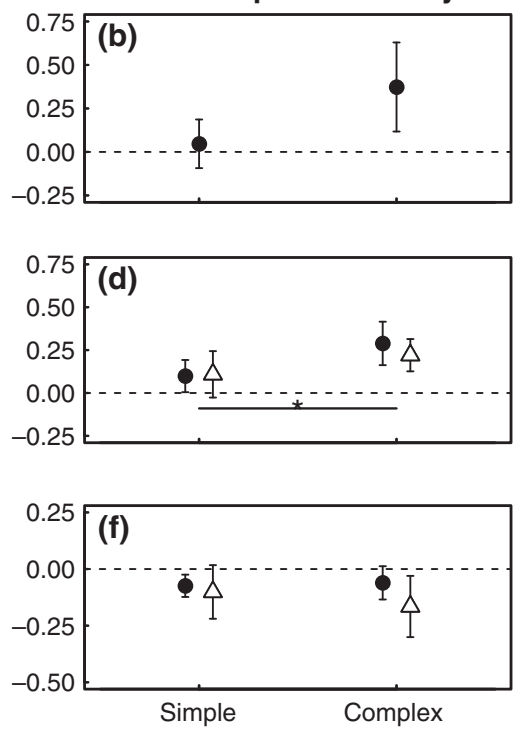

In-field plant diversity
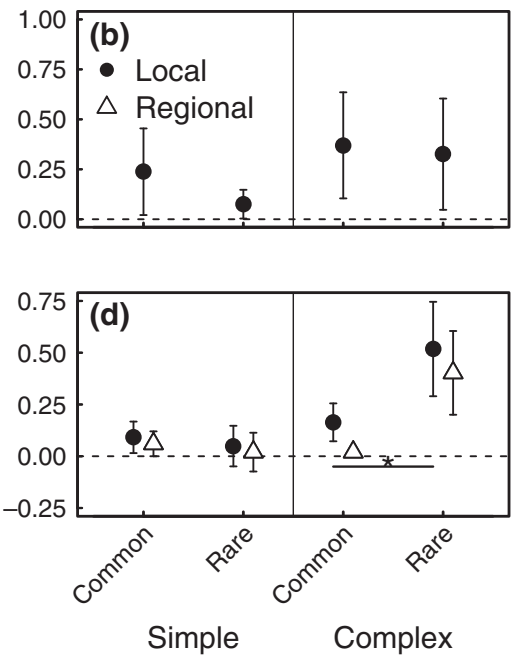

FIGURE 3 Effects of landscape complexity on the entire arthropod community in organic vs. conventional farms (left column) and fields with high vs. low in-field plant diversity (right column). Each graph shows the mean log-response ratio $( \pm S E)$ for studies in simple $(\leq 20 \%$ natural habitat) or complex ( $>20 \%$ natural habitat) landscapes for (a, b) abundance, (c, d) richness, and (e, f) evenness. A "*" below a set of means indicates a significant difference between means at the habitat complexity levels (determined via paired $t$-tests; $\alpha=0.1$; Tables S9-S12)
FIGURE 4 Effects of farm management schemes on abundance $(a, b)$ and richness (c, d) of common vs. rare taxa in simple and complex landscapes. Mean logresponse ratios ( $\pm S E$ ) of (left column) adopting organic farming and (right column) promoting in-field plant diversity. A "*" below a pair of means indicates a significant difference between rare and common taxa within a landscape complexity category (determined via paired t-tests; $\alpha=0.1$; Tables S19) plant diversification on abundance and diversity were consistent across crop cultivation periods (Tables S11, S12).

\section{DISCUSSION}

Our global meta-analysis showed that both organic farming and infield plant diversification strongly increased arthropod abundance and richness, but had weaker effects on evenness. The minimal evenness decreases on diversified farms reflected the presence of more rare taxa. Emerging evidence suggests that rare taxa contribute to individual ecosystem services less than common taxa (Kleijn et al., 2015; Schwartz et al., 2000), although they may be important for maintenance of multiple ecosystem services across time and space (Isbell et al., 2011; Soliveres et al., 2016). Thus, while organic farming and plant diversification promote arthropod biodiversity conservation goals, their impacts on ecosystem services may be nuanced.
The positive effects of both organic farming and in-field plant diversification were greatest for two groups of beneficial arthropods: pollinators and predators. Thus, both schemes may increase agroecosystem sustainability by promoting key ecosystem service providers without boosting pest (herbivore) densities.

Previous meta-analyses have investigated how organic farming and, to a lesser extent, in-field plant diversification, affect arthropod abundance and richness (e.g., Batáry et al., 2011; Bengtsson et al., 2005; Chaplin-Kramer et al., 2011; Scheper et al., 2013; Shackelford et al., 2013; Tuck et al., 2014). Our study extends upon this work by (i) combining data on multiple arthropod functional groups (but see Shackelford et al., 2013), and (ii) examining the type and scale of diversity across a variety of crop types. As such, we offer a more comprehensive understanding of when and how farm management schemes alter arthropod biodiversity. Our findings caution that the frequent use of richness as the sole proxy for biodiversity fails to reflect the full impacts of farming practices on biologic communities. 
While multiple studies have shown that organic farming boosts richness (e.g., Bengtsson et al., 2005; Tuck et al., 2014), we found that evenness decreased: an outcome that was due mainly to promotion of rare species. Species richness might be increased by conservation practices that target specific taxa, but the promotion of evenness requires practices that can simultaneously balance the abundances of many taxa (Crowder et al., 2010, 2012). Finally, our results highlight the necessity of targeting farm management within the context of local conditions (Cunningham et al., 2013; Saunders, Peisley, Rader, \& Luck, 2016). For example, our results suggest that farmers in Mediterranean biomes might see greater arthropod richness gains by increasing in-field plant diversity than by farming organically, while farmers growing annual crops may be more likely to boost arthropod abundance with organic farming.

Disentangling relationships between biodiversity components at local and regional scales can inform patterns of community assembly and mechanisms that shape community structure (Gering \& Crist, 2002; Wang \& Loreau, 2014). We found that regional diversity positively correlated with local diversity under both management schemes. Further, organic farming increased richness at both scales, although local effects were stronger than regional ones. One possible explanation is that diversified farming practices increase the heterogeneity of local communities (e.g., Ponisio et al., 2016), which could lead to greater regional diversity. Another possibility is that diversified fields serve as source habitats within a matrix of crop and non-crop habitats across farming landscapes (M'Gonigle, Ponisio, Cutler, \& Kremen, 2015). Further, the benefits of diversification practices on local communities in fields can be strongly mediated by regional species pools across farming landscapes (Gering \& Crist, 2002).

Our results, in combination with another recent meta-analysis (Schneider et al., 2014), suggest that mobility of organisms can determine whether the benefits of farm diversification accrue at both local and regional scales. While we show that organic farming can boost arthropod diversity at local and regional scales, Schneider et al. (2014) found that organic farming increased plant, earthworm, and spider richness at field but not regional scales. These groups of organisms tend to have limited dispersal capacity, particularly plants and earthworms. Thus, their local communities may be structured more by competition than long-distance dispersal (Gering \& Crist, 2002), which would limit the similarity between communities within and across fields. At the same time, Schneider et al. (2014) found that organic farming boosted the richness of bees, a more mobile group of organisms, by approximately $25 \%$ at the local scale and $15 \%$ at the regional scale. We likewise found that diversified farming increased abundance, and local and regional richness, of mobile pollinators, but had less impact on detritivores that tend to have lower mobility (Sattler, Duelli, Obrist, Arlettaz, \& Moretti, 2010).

Overall, our results are consistent with mounting evidence that farm management and landscape complexity interactively affect arthropod biodiversity (e.g., Batáry et al., 2011; Kennedy et al., 2013; Rusch, Valantin-Morison, Sarthou, \& Roger-Estrade, 2010; Tuck et al., 2014), although results across studies reveal sometimes conflicting patterns (Kleijn et al., 2011; Tscharntke et al., 2012; Tuck et al., 2014). For example, agri-environment schemes that promote low input, low disturbance, and diverse farms are sometimes most effective in fostering biodiversity in structurally simple landscapes (Batáry et al., 2011; Scheper et al., 2013). This presumably occurs because simple landscapes fail to satisfy the resource needs of many species, such that these species may disperse into diverse farms to seek resources (Kremen \& Miles, 2012; Tscharntke et al., 2005). In contrast, we found that impacts of organic farming and plant diversification on arthropod richness were heightened for fields embedded in complex landscapes. This could occur if complex landscapes support more diverse species pools that can respond positively to farm management (Duelli \& Obrist, 2003; Hillebrand, Bennett, \& Cadotte, 2008; Kennedy et al., 2013). Consistent with this hypothesis, we showed that organic farming in complex landscapes preferentially increased richness of rare taxa locally (i.e., in fields) and regionally (i.e., across landscapes). Importantly, the interactive effects of landscape complexity and on-farm management may differ across arthropod functional groups with varying capacity to move across landscapes (Chaplin-Kramer et al., 2011; Tscharntke et al., 2005). However, the only interaction between landscape complexity and management schemes we found was for richness of herbivores, a group with considerable variation in mobility among taxa (Sattler et al., 2010).

Ideally, increases in abundance and diversity of arthropods on farms would enhance the provisioning of ecosystem services (Kremen \& Miles, 2012). However, empirical studies have provided mixed evidence. In-field plant diversification and increased landscape complexity have been found to promote predator abundance and diversity with no change in pest control levels (Chaplin-Kramer et al., 2011; Rusch et al., 2016) or reduced crop damage (Letourneau et al., 2011). The relationship between biodiversity and ecosystem services on farms is thus likely strongly mediated by species' abundances and functional roles. For example, Northfield et al. (2010) found that greater predator richness increased pest control, but only with high predator densities where complementarity among predator species was fully realized. Increases in pollinator richness can have minimal impacts on ecosystem services when richness gains are associated with rare species that contribute little to pollination (Kleijn et al., 2015; Winfree et al., 2015). Increasing wild pollinator richness on large farms ( $>14 \mathrm{ha}$ ) only increases fruit set when wild pollinator density is also high (Garibaldi et al., 2016). Higher predator species evenness on organic farms has also been shown to translate to increased pest control, with the potential to reduce yield gaps compared with conventional agriculture (Crowder et al., 2010). However, models suggest that decreased evenness could also lead to greater ecosystem services when abundance of common species that are effective ecosystem services providers increases at the expense of rare species that are functionally less important (Crowder \& Jabbour, 2014), a result seen with pollinators in agricultural systems (Kleijn et al., 2015; Winfree et al., 2015). The combination of context-specific responses to farm management schemes shown by this study and biodiversity-ecosystem functioning relationships that depend on species' abundances and functional traits suggest that the effects of 
diversified farming on ecosystem services are likely to depend on taxon, biome, landscape, and crop characteristics.

By promoting biodiversity and abundance of arthropods, diversified agriculture could provide a multitude of other benefits (Oliver et al., 2015). Biodiversity can help maintain stability of ecosystem processes through mechanisms such as response diversity and functional redundancy (Cardinale et al., 2012; Mori, Furukawa, \& Sasaki, 2013). Arthropod richness gains in response to organic farming and plant diversification, such as those documented here, could guard against the loss of ecological function by supporting multiple species that occupy similar functional niches (functional redundancy) or that are functionally similar but respond differentially to environmental change (response diversity; Elmqvist et al., 2003). The abundance and richness increases we detected for pollinators and predators but not for herbivores suggest that the two former groups may benefit more from these stabilizing processes. Resilient systems must also exhibit multiple ecosystem functions (multifunctionality) as environmental conditions and arthropod populations fluctuate. Increases in rare taxa, as detected in this study, may be critical for multifunctionality (Isbell et al., 2011; Soliveres et al., 2016) and even for single ecosystem functions (Mouillot et al., 2013; Zavaleta \& Hulvey, 2004). Thus, regional-scale refuges for rare species may ensure resilient agricultural systems.

Overall, our results suggest that both organic farming and in-field plant diversification promote biodiversity on farms. Moreover, these two schemes might have interactive effects on farm productivity. Practices such as multicropping (plant diversification) and longer, more diverse, crop rotations can reduce the yield gaps between organic and conventional agriculture (Ponisio et al., 2015), and increase the profitability of organic relative to conventional systems (Crowder \& Reganold, 2015). Diversified small farms are increasingly being replaced by large, simplified, and intensive monoculture production systems (Bennett, Bending, Chandler, Hilton, \& Mills, 2012; Tscharntke et al., 2005). This is problematic because intensified farming reduces the long-term sustainability of agroecosystems, thereby threatening global food security (Ray, Ramankutty, Mueller, West, \& Foley, 2012). One of the greatest challenges of the 21st century is meeting the food, fiber, and energy needs of a growing human population, while maintaining farm sustainability and ecosystem functioning (Tilman, Balzer, Hill, \& Befort, 2011). Our study underscores that adopting organic farming or in-field plant diversification practices might aid society in attaining these goals.

\section{ACKNOWLEDGEMENTS}

We thank Kayla Fillion and Gavin Smetzler for data assistance, and Lea D. Schneider for help with the graphical abstract. EML and DC were supported by the National Institute of Food and Agriculture, U.S. Department of Agriculture, under award number 2014-5110622096. BMF was supported by the National Council for Scientific and Technological Development-CNPq, Brasília, Brazil \#305062/ 2007-7. SGP and MO were supported by the Felix Trust and STEP Project (EC FP7 244090).

\section{DATA ACCESSIBILITY}

Data and scripts available at: https://doi.org/10.5281/zenodo. 439109

\section{REFERENCES}

Barton, K. (2014). MuMIn: Multi-model inference. R package v. 1.13.14. Retrieved from https://cran.r-project.org/web/packages/MuMln/ MuMln.pdf

Batáry, P., Báldi, A., Kleijn, D., \& Tscharntke, T. (2011). Landscape-moderated biodiversity effects of agri-environmental management: A metaanalysis. Proceedings of the Royal Society B: Biological Sciences, 278, 1894-1902.

Batáry, P., Dicks, L. V., Kleijn, D., \& Sutherland, W. J. (2015). The role of agri-environment schemes in conservation and environmental management. Conservation Biology, 29, 1006-1016.

Bates, D., Mächler, M., Bolker, B., \& Walker, S. (2014). Fitting linear mixed-effects models using Ime4. arXiv:1406.5823.

Bengtsson, J., Ahnström, J., \& Weibull, A.-C. (2005). The effects of organic agriculture on biodiversity and abundance: A meta-analysis. Journal of Applied Ecology, 42, 261-269.

Bennett, A. J., Bending, G. D., Chandler, D., Hilton, S., \& Mills, P. (2012). Meeting the demand for crop production: The challenge of yield decline in crops grown in short rotations. Biological Reviews, 87, 52-71.

Burnham, K. P., \& Anderson, D. R. (1998). Model selection and multimodel inference: A practical information-theoretic approach, 2nd edn. New York: Springer-Verlag. 488 pp.

Cardinale, B. J., Duffy, J. E., Gonzalez, A., Hooper, D. U., Perrings, C., Venail, P., ... Naeem, S. (2012). Biodiversity loss and its impact on humanity. Nature, 486, 59-67.

Chao, A., \& Jost, L. (2012). Coverage-based rarefaction and extrapolation: Standardizing samples by completeness rather than size. Ecology, 93, 2533-2547.

Chaplin-Kramer, R., O'Rourke, M. E., Blitzer, E. J., \& Kremen, C. (2011). A meta-analysis of crop pest and natural enemy response to landscape complexity. Ecology Letters, 14, 922-932.

Crowder, D. W., \& Jabbour, R. (2014). Relationships between biodiversity and biological control in agroecosystems: Current status and future challenges. Biological Control, 75, 8-17.

Crowder, D. W., Northfield, T. D., Gomulkiewicz, R., \& Snyder, W. E. (2012). Conserving and promoting evenness: Organic farming and fire-based wildland management as case studies. Ecology, 93, 20012007.

Crowder, D. W., Northfield, T. D., Strand, M. R., \& Snyder, W. E. (2010). Organic agriculture promotes evenness and natural pest control. Nature, 466, 109-112.

Crowder, D. W., \& Reganold, J. P. (2015). Financial competitiveness of organic agriculture on a global scale. Proceedings of the National Academy of Sciences, 112, 7611-7616.

Cunningham, S. A., Attwood, S. J., Bawa, K. S., Benton, T. G., Broadhurst, L. M., Didham, R. K., ... Lindenmayer, D. B. (2013). To close the yield-gap while saving biodiversity will require multiple locally relevant strategies. Agriculture, Ecosystems and Environment, 173, 20-27.

De Palma, A., Abrahamczyk, S., Aizen, M. A., Albrecht, M., Basset, Y., Bates, A., .. Purvis, A. (2016). Predicting bee community responses to land-use changes: Effects of geographic and taxonomic biases. Scientific Reports, 6, 31153.

Duelli, P., \& Obrist, M. K. (2003). Regional biodiversity in an agricultural landscape: The contribution of seminatural habitat islands. Basic and Applied Ecology, 4, 129-138.

Duncan, C., Thompson, J. R., \& Pettorelli, N. (2015). The quest for a mechanistic understanding of biodiversity-ecosystem services 
relationships. Proceedings of the Royal Society B: Biological Sciences, 282, 20151348.

Elmqvist, T., Folke, C., Nyström, M., Peterson, G., Bengtsson, J., Walker, B., \& Norberg, J. (2003). Response diversity, ecosystem change, and resilience. Frontiers in Ecology and the Environment, 1, 488-494.

Fahrig, L., Girard, J., Duro, D., Pasher, J., Smith, A., Javorek, S., ... Tischendorf, L. (2015). Farmlands with smaller crop fields have higher within-field biodiversity. Agriculture, Ecosystems and Environment, 200, 219-234.

FAO AGPC (2000). Ecocrop. Retrieved from http://ecocrop.fao.org/ecoc rop/srv/en/cropFindForm

Garibaldi, L. A., Carvalheiro, L. G., Leonhardt, S. D., Aizen, M. A., Blaauw, B. R., Isaacs, R., ... Winfree, R. (2014). From research to action: Enhancing crop yield through wild pollinators. Frontiers in Ecology and the Environment, 12, 439-447.

Garibaldi, L. A., Carvalheiro, L. G., Vaissière, B. E., Gemmill-Herren, B., Hipólito, J., Freitas, B. M., ... Zhang, H. (2016). Mutually beneficial pollinator diversity and crop yield outcomes in small and large farms. Science, 351, 388-391.

Garibaldi, L. A., Steffan-Dewenter, I., Winfree, R., Aizen, M. A., Bommarco, R., Cunningham, S. A., ... Klein, A. M. (2013). Wild pollinators enhance fruit set of crops regardless of honey bee abundance. Science, 339, 1608-1611.

Gering, J. C., \& Crist, T. O. (2002). The alpha-beta-regional relationship: Providing new insights into local-regional patterns of species richness and scale dependence of diversity components. Ecology Letters, 5, 433-444.

Gotelli, N. J., \& Colwell, R. K. (2011). Estimating species richness. In A. E. Magurran, \& B. J. McGill (Eds.), Biological diversity (pp. 39-54). New York: Oxford University Press.

Hedges, L. V., Gurevitch, J., \& Curtis, P. S. (1999). The meta-analysis of response ratios in experimental ecology. Ecology, 80, 1150-1156.

Hillebrand, H., Bennett, D. M., \& Cadotte, M. W. (2008). Consequences of dominance: A review of evenness effects on local and regional ecosystem processes. Ecology, 89, 1510-1520.

Højsgaard, S., \& Halekoh, U. (2013). doBy: doBy - Groupwise summary statistics, LSmeans, general linear contrasts, various utilities. R package v. 4.5-11. Retrieved from https://cran.rstudio.com/web/packages/ doBy/index.html

Isbell, F., Calcagno, V., Hector, A., Connolly, J., Harpole, W. S., Reich, P. B., ... Loreau, M. (2011). High plant diversity is needed to maintain ecosystem services. Nature, 477, 199-202.

Jin, Z.-C., Zhou, X.-H., \& He, J. (2015). Statistical methods for dealing with publication bias in meta-analysis. Statistics in Medicine, 34, 343360.

Kennedy, C. M., Lonsdorf, E., Neel, M. C., Williams, N. M., Ricketts, T. H., Winfree, R., ... Kremen, C. (2013). A global quantitative synthesis of local and landscape effects on wild bee pollinators in agroecosystems. Ecology Letters, 16, 584-599.

Kindt, R., \& Coe, R. (2005). Tree diversity analysis. A manual and software for common statistical methods in ecology and biodiversity studies. World Agroforestry Centre (ICRAF), Nairobi, 196 pp.

Kleijn, D., Rundlöf, M., Scheper, J., Smith, H. G., \& Tscharntke, T. (2011). Does conservation on farmland contribute to halting the biodiversity decline? Trends in Ecology and Evolution, 26, 474-481.

Kleijn, D., Winfree, R., Bartomeus, I., Carvalheiro, L. G., Henry, M., Isaaces, R., ... Potts, S. G. (2015). Delivery of crop pollination services is an insufficient argument for wild pollinator conservation. Nature Communications, 6, 7414.

Kremen, C., \& Miles, A. (2012). Ecosystem services in biologically diversified versus conventional farming systems: Benefits, externalities, and trade-offs. Ecology and Society, 17, 40.

Letourneau, D. K., Armbrecht, I., Rivera, B. S., Lerma, J. M., Carmona, E. J., Daza, M. C., ... Trujillo, A. R. (2011). Does plant diversity benefit agroecosystems? A synthetic review. Ecological Applications, 21, 9-21.
Loiseau, N., \& Gaertner, J.-C. (2015). Indices for assessing coral reef fish biodiversity: The need for a change in habits. Ecology and Evolution, 5, 4018-4027.

Matson, P. A., Parton, W. J., Power, A. G., \& Swift, M. J. (1997). Agricultural intensification and ecosystem properties. Science, 277, 504-509.

M'Gonigle, L. K., Ponisio, L. C., Cutler, K., \& Kremen, C. (2015). Habitat restoration promotes pollinator persistence and colonization in intensively managed agriculture. Ecological Applications, 25, 1557-1565.

Mori, A. S., Furukawa, T., \& Sasaki, T. (2013). Response diversity determines the resilience of ecosystems to environmental change. Biological Reviews, 88, 349-364.

Mouillot, D., Bellwood, D. R., Baraloto, C., Chave, J., Galzin, R., HarmelinVivien, M., ... Thuiller, W. (2013). Rare species support vulnerable functions in high-diversity ecosystems. PLOS Biology, 11, e1001569.

Northfield, T. D., Snyder, G. B., Ives, A. R., \& Snyder, W. E. (2010). Niche saturation reveals resource partitioning among consumers. Ecology Letters, 13, 338-348.

Oliver, T. H., Isaac, N. J. B., August, T. A., Woodcock, B. A., Roy, D. B., \& Bullock, J. M. (2015). Declining resilience of ecosystem functions under biodiversity loss. Nature Communications, 6, 10122.

Pasari, J. R., Levi, T., Zavaleta, E. S., \& Tilman, D. (2013). Several scales of biodiversity affect ecosystem multifunctionality. Proceedings of the National Academy of Sciences, 110, 10219-10222.

Pasher, J., Mitchell, S. W., King, D. J., Fahrig, L., Smith, A. C., \& Lindsay, K. E. (2013). Optimizing landscape selection for estimating relative effects of landscape variables on ecological responses. Landscape Ecology, 28, 371-383.

Ponisio, L. C., M'Gonigle, L. K., \& Kremen, C. (2016). On-farm habitat restoration counters biotic homogenization in intensively managed agriculture. Global Change Biology, 22, 704-715.

Ponisio, L. C., M'Gonigle, L. K., Mace, K. C., Palomino, J., de Valpine, P., \& Kremen, C. (2015). Diversification practices reduce organic to conventional yield gap. Proceedings of the Royal Society B: Biological Sciences, 282, 20141396.

Potts, S. G., Imperatriz-Fonseca, V. L., Ngo, H. T., Biesmeijer, J. C., Breeze, T. D., Dicks, L. V., ... Viana, B. F. (Eds.) (2016). Summary for policymakers of the assessment report of the Intergovernmental SciencePolicy Platform on Biodiversity and Ecosystem Services on pollinators, pollination and food production. Secretariat of the Intergovernmental Science-Policy Platform on Biodiversity and Ecosystem Services, Bonn, Germany, 36 pp.

Puech, C., Baudry, J., Joannon, A., Poggi, S., \& Aviron, S. (2014). Organic vs. conventional farming dichotomy: Does it make sense for natural enemies? Agriculture, Ecosystems and Environment, 194, 48-57.

$R$ Core Team (2014).R: A language and environment for statistical computing. R Foundation for Statistical Computing, Vienna.

Ray, D. K., Ramankutty, N., Mueller, N. D., West, P. C., \& Foley, J. A. (2012). Recent patterns of crop yield growth and stagnation. Nature Communications, 3, 1293.

Rosario-Martinez, H. (2013). phia: Post-Hoc Interaction Analysis. R package v. 0.2-0. Retrieved from https://cran.rstudio.com/web/packages/ phia/index.html

Rusch, A., Chaplin-Kramer, R., Gardiner, M. M., Hawro, V., Holland, J., Landis, D., ... Bommarco, R. (2016). Agricultural landscape simplification reduces natural pest control: A quantitative synthesis. Agriculture, Ecosystems and Environment, 221, 198-204.

Rusch, A., Valantin-Morison, M., Sarthou, J.-P., \& Roger-Estrade, J. (2010). Biological control of insect pests in agroecosystems: Effects of crop management, farming systems, and seminatural habitats at the landscape scale: A review. In D. L. Sparks (Ed.), Advances in agronomy, Vol. 109 (pp. 219-259). Cambridge, MA, USA: Academic Press.

Sattler, T., Duelli, P., Obrist, M. K., Arlettaz, R., \& Moretti, M. (2010). Response of arthropod species richness and functional groups to urban habitat structure and management. Landscape Ecology, 25, 941-954. 
Saunders, M. E., Peisley, R. K., Rader, R., \& Luck, G. W. (2016). Pollinators, pests, and predators: Recognizing ecological trade-offs in agroecosystems. Ambio, 45, 4-14.

Scheper, J., Holzschuh, A., Kuussaari, M., Potts, S. G., Rundlöf, M., Smith, H. G., \& Kleijn, D. (2013). Environmental factors driving the effectiveness of European agri-environmental measures in mitigating pollinator loss - a meta-analysis. Ecology Letters, 16, 912-920.

Schneider, M. K., Lüscher, G., Jeanneret, P., Arndorfer, M., Ammari, Y., Bailey, D., ... Herzog, F. (2014). Gains to species diversity in organically farmed fields are not propagated at the farm level. Nature Communications, 5, 4151.

Schwartz, M. W., Brigham, C. A., Hoeksema, J. D., Lyons, K. G., Mills, M. H., \& van Mantgem, P. J. (2000). Linking biodiversity to ecosystem function: Implications for conservation ecology. Oecologia, 122, 297 305.

Shackelford, G., Steward, P. R., Benton, T. G., Kunin, W. E., Potts, S. G., Biesmeijer, J. C., \& Sait, S. M. (2013). Comparison of pollinators and natural enemies: A meta-analysis of landscape and local effects on abundance and richness in crops. Biological Reviews, 88, 10021021.

Soliveres, S., Manning, P., Prati, D., Gossner, M. M., Alt, F., Arndt, H., ... Allan, E. (2016). Locally rare species influence grassland ecosystem multifunctionality. Philosophical Transactions of the Royal Society B: Biological Sciences, 371, 20150269.

Sterne, J. A. C., \& Egger, M. (2001). Funnel plots for detecting bias in meta-analysis: Guidelines on choice of axis. Journal of Clinical Epidemiology, 54, 1046-1055.

Tilman, D., Balzer, C., Hill, J., \& Befort, B. L. (2011). Global food demand and the sustainable intensification of agriculture. Proceedings of the National Academy of Sciences, 108, 20260-20264.

Tscharntke, T., Klein, A. M., Kruess, A., Steffan-Dewenter, I., \& Thies, C. (2005). Landscape perspectives on agricultural intensification and biodiversity - ecosystem service management. Ecology Letters, 8, 857874.

Tscharntke, T., Tylianakis, J. M., Rand, T. A., Didham, R. K., Fahrig, L., Batáry, P., ... Westphal, C. (2012). Landscape moderation of biodiversity patterns and processes - eight hypotheses. Biological Reviews, 87, 661-685.

Tuck, S. L., Winqvist, C., Mota, F., Ahnström, J., Turnbull, L. A., \& Bengtsson, J. (2014). Land-use intensity and the effects of organic farming on biodiversity: A hierarchical meta-analysis. Journal of Applied Ecology, 51, 746-755.

Wang, S., \& Loreau, M. (2014). Ecosystem stability in space: $\alpha, \beta$ and $\gamma$ variability. Ecology Letters, 17, 891-901.

Wasserstein, R. L., \& Lazar, N. A. (2016). The ASA's statement on pvalues: Context, process, and purpose. The American Statistician, 70, 129-133.

Wickham, H. (2007). Reshaping data with the reshape package. Journal of Statistical Software, 21, 1-20.

Wilsey, B., \& Stirling, G. (2006). Species richness and evenness respond in a different manner to propagule density in developing prairie microcosm communities. Plant Ecology, 190, 259-273.

Winfree, R., Fox, J. W., Williams, N. M., Reilly, J. R., \& Cariveau, D. P. (2015). Abundance of common species, not species richness, drives delivery of a real-world ecosystem service. Ecology Letters, 18, 626635.

Wittebolle, L., Marzorati, M., Clement, L., Balloi, A., Daffonchio, D., Heylen, K., ... Boon, N. (2009). Initial community evenness favours functionality under selective stress. Nature, 458, 623-626.

Zavaleta, E. S., \& Hulvey, K. B. (2004). Realistic species losses disproportionately reduce grassland resistance to biological invaders. Science, 306, 1175-1177.

\section{SUPPORTING INFORMATION}

Additional Supporting Information may be found online in the supporting information tab for this article.

How to cite this article: Lichtenberg EM, Kennedy CM, Kremen C, et al. A global synthesis of the effects of diversified farming systems on arthropod diversity within fields and across agricultural landscapes. Glob Change Biol. 2017;00:1-12. https://doi.org/10.1111/gcb.13714 